\title{
KAP On Connective Tissue Grafts in Implant Aesthetics
}

\author{
Rachel Paul', Ashok V², Kiran Kumar ${ }^{3}$ and Dhanraj Ganapathy ${ }^{4}$ \\ ${ }^{1}$ Saveetha Dental college \& Hospitals, Saveetha Institute of Medical and technical Sciences, Saveetha University, \\ Chennai 600077 Tamil Nadu, India \\ ${ }^{2}$ Professor and Head (Admin), Department of Prosthodontics Saveetha Dental College and Hospitals Saveetha \\ Institute of Medical and Technical Sciences, Saveetha University Chennai, India \\ ${ }^{3}$ Senior Lecturer Department of Prosthodontics Saveetha Dental College and Hospitals Saveetha Institute of \\ Medical and Technical Sciences, Saveetha University Chennai, India \\ ${ }^{4}$ Professor and Head (Academic), Department of Prosthodontics Saveetha Dental College and Hospitals Saveetha \\ Institute of Medical and Technical Sciences, Saveetha University Chennai, India
}

\begin{abstract}
Restoring extreme loss of bone and soft tissue especially in the aesthetic zone is unpredictable and difficult to manage. The aim of this study is to evaluate the knowledge and awareness of connective tissue grafts in implant aesthetics. A questionnaire of 10 questions is prepared and distributed among the dental practitioners and undergraduate students. Some of the questions include year of study, ideal location to obtain graft, ideal thickness of the graft etc. The results are obtained and tabulated. The knowledge and attitude towards connective tissue grafts in implant aesthetics is poor among the dental practitioners. Due to the lack of knowledge, this can lead to failure in implant or in patient satisfaction. In recent years, the prosthetic rehabilitation of partially edentulous jaws has been increasingly influenced by patients' growing interest and expectation regarding sites of aesthetics priority. Hence gaining knowledge and attitude towards connective grafts in implant aesthetics will help in patient satisfaction as well as success of the implant.
\end{abstract}

KEY WORDS: CONNECTIVE TISSUE GRAFTING; IMPLANT; AESTHETICS; PATIENT SATISFACTION; KNOWLEDGE.

\section{INTRODUCTION}

Dental implants are becoming the most preferred treatment of choice to replace missing teeth, especially if the adjacent teeth are free of restorations. With minimal bone width present, the implant placement becomes a challenge and often results in gingival recession and dehiscence around the implant. (Kassab, 2010) The successful use of dental implants to replace missing teeth has become one of the most popular, exciting, and

\section{ARTICLE INFORMATION}

${ }^{*}$ Corresponding Author: dhanrajmganapathy@yahoo.co.in Received 28th July 2020 Accepted after revision 26th Sep 2020 Print ISSN: 0974-6455 Online ISSN: 2321-4007 CODEN: BBRCBA

Thomson Reuters ISI Web of Science Clarivate Analytics USA and Crossref Indexed Journal

\section{Clarivate crossef}

NAAS Journal Score 2020 (4.31) SJIF: 2020 (7.728)

A Society of Science and Nature Publication,

Bhopal India 2020. All rights reserved.

Online Contents Available at: http//www.bbrc.in/

Doi: http://dx.doi.org/10.21786/bbrc/13.8/170 evolving areas of clinical dentistry. When implants are thought of as a treatment option, treatment planning has become more complex for the dental practitioner, and an interdisciplinary team approach is needed. Failure to demonstrate such an approach might lead to an undesirable implant complication. Both the quantity and the quality of the alveolar bone must be assessed when an implant placement is considered.

The anterior maxilla region is an anatomically difficult region for dental implantation. Soft and hard tissue augmentations are often needed to restore the affected site. A sufficient bone density and volume is needed for stable placement of dental implants. (Buser, Martin and Belser, 2004) (Zhang, Skrypczak and Weltman, 2015) (McAllister and Haghighat, 2011) In addition, aesthetic outcome is an important parameter for the patient. The main aesthetic objective for patients is to maintain a harmonious gingival contour with intact papillae and without abrupt changes. Placement of dental implants

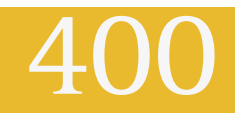


in the anterior maxillary region can be achieved by different methods.(Belser et al., 1998) The optimal method is dependent on anatomical parameters such as bone volume, bone density, alveolar crest position, adjacent teeth, and gingival morphology.

The success in rehabilitating the stomatognathic system including the aesthetics depends on the optimization of the algorithms specific to the pre-prosthetic, pro-implant and prosthetic stage. However, the anatomical limits, occlusal space management, occlusal stability and periodontal status must be considered prior to the planning of the esthetic parameters for the future prosthetic restoration (Forna and Agop-Forna, 2019) Aesthetic outcomes are important for successful dental implantation which are determined by the smile and lip line. Previously our department has published extensive research on various aspects of prosthetic dentistry ('Evaluation of Corrosive Behavior of Four Nickel-chromium Alloys in Artificial Saliva by Cyclic Polarization Test:An in vitro Study', 2017; Ganapathy, Kannan and Venugopalan, 2017; Jain, 2017a, 2017b; Ranganathan, Ganapathy and Jain, 2017; Ariga et al., 2018; Gupta, Ariga and Deogade, 2018; Anbu et al., 2019; Duraisamy et al., 2019; 2019; Ashok and Ganapathy, 2019;:Varghese, Ramesh and Veeraiyan,), this vast research experience has inspired us to do research on connective tissue graft in implant aesthetics. The aim of the study is to evaluate the knowledge attitude and practise on connective tissue used in implant aesthetics.

\section{MATERIAL AND METHODS}

A questionnaire of 10 questions is prepared and are distributed among the undergraduates. Some of the questions involved years of study, the different types of grafts used in implant aesthetics, the conditions requiring grafts. The results are obtained and tabulated.

\section{RESULTS AND DISCUSSION}

A total of 100 students participated in this study and answered the survey questions. The knowledge and awareness among the students based on the success rate of connective tissue grafts compared to other tissue grafts were positive (65\%) (figure 1). The most common answer for the aesthetic considerations of the connective tissue grafts compared to the other tissue grafts by the students was not sure (45\%) (figure 2) The most common answer for the ideal thickness of the connective tissue graft was found to be $1.5-2 \mathrm{~mm}(41.67 \%)$ (figure 3). The most common answer received for the ideal location of an implant connective graft is $5-6 \mathrm{~mm}$ to the gingival margin of the palatal aspects of the maxillary premolars and the mesial half of the maxillary first molar. (35\%) (figure 4).

In the past two decades, the influence of aesthetic values on restorative dentistry and prosthodontics have been increasing dramatically. Various novels and articles have been specifically developed leading to less invasive approaches on one side and having highly predictable results on the other side. (Prasad, Shetty and Mehra, 2013) (Kloukos et al., 2014) (Ehrenfest et al., 2010) Currently, anterior fixed partial dentures can frequently provide long lasting aesthetics and ultimately create the almost perfect illusion, making it difficult to detect that missing teeth have been replaced by a prosthesis. As a consequence, any implant borne prosthesis will be compared to the aesthetic and functional standards that can be achieved today by conventional tooth supported restorations.

Figure 1: Bar graph represents the knowledge and awareness of students on the success rate of tissue grafts after an implant placement. The $\mathrm{x}$ axis of the graph represents the knowledge on success rate and the $y$ axis represents the number of participants in the study. The graph infers that most of the students knew about the success rate of connective tissue grafts compared to other tissue grafts used for implant aesthetics depicted as grey in the graph(65.0\% of the students) followed by some not sure shown in blue colour ( $25.0 \%$ )

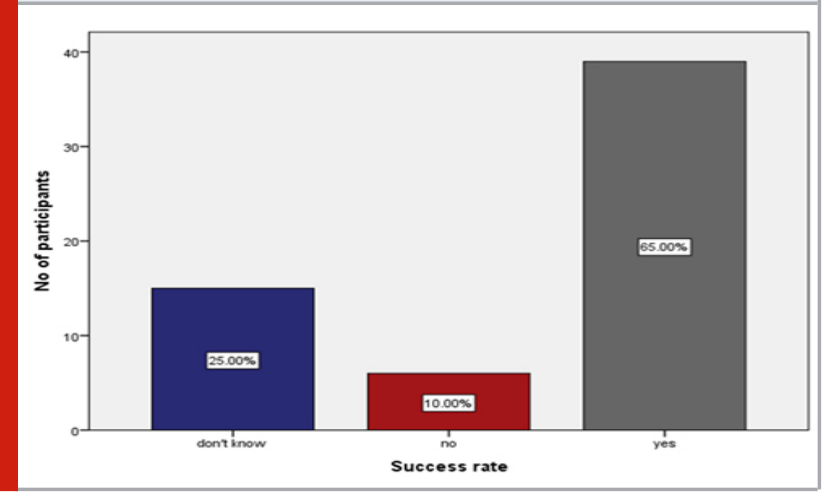

Figure 2: Bar graph represents the knowledge and awareness of students on the aesthetic considerations of tissue grafts compared to other grafts after an implant placement. The $\mathrm{x}$ axis of the graph represents the knowledge on aesthetic consideration of the graft and the $y$ axis represents the number of participants in the study. Most of the students were not sure of the answer ie. $45.0 \%$ of the students shown in blue in the graph followed by $36.67 \%$ of the students answered yes shown as grey colour.

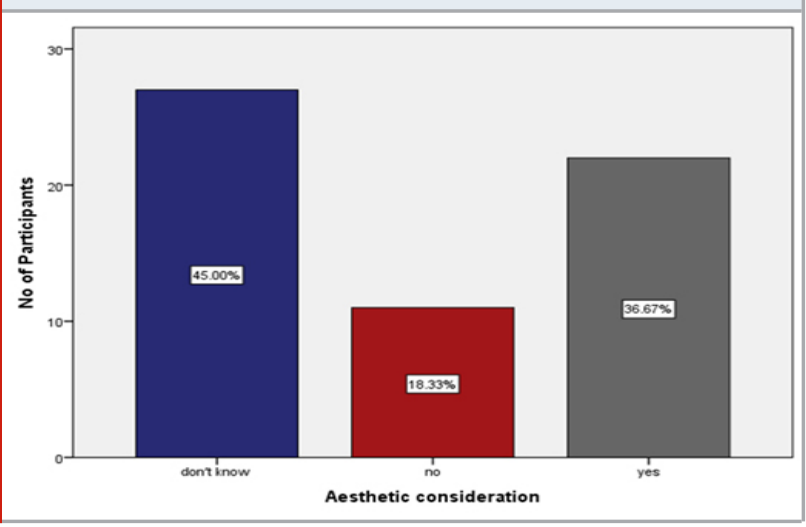


Figure 3: Graph represents the survey knowledge and awareness of the students on ideal thickness of the tissue graft that can be used after an implant placement. The $\mathrm{x}$ axis of the graph represents the knowledge on the ideal thickness of the graft and the $y$ axis represents the number of participants in the study. The answer commonly received was found to be $1.5-2 \mathrm{~mm}(41.67 \%)$ shown as grey colour followed by $0.5-1 \mathrm{~mm}$ thickness shown as blue colour $(28.37 \%)$.

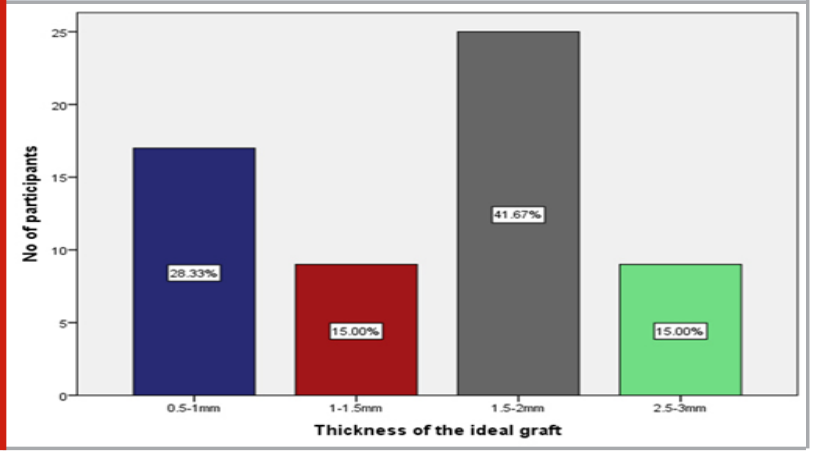

Figure 4: Graph represents the knowledge and awareness of students on the ideal location of the connective tissue graft. The $\mathrm{x}$ axis of the graph represents the knowledge on the ideal location of the graft and the $y$ axis represents the number of participants in the study. The most common answer obtained was $5-6 \mathrm{~mm}$ (shown as blue colour in th graph) apical to the gingival margin of the tooth (35\%) followed by $6-7 \mathrm{~mm}(31.67 \%)$ shown in red in the graph.

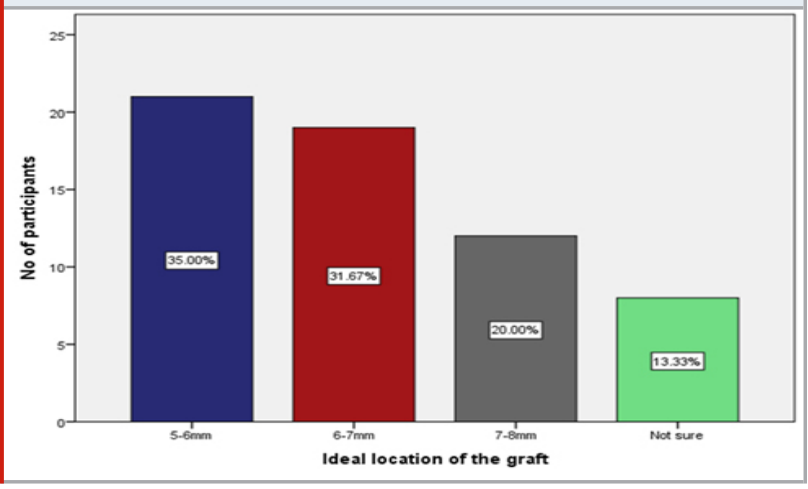

Patients report to the practitioners asking for replacement of teeth and not directly asking for implants. They would like to have their teeth replaced in the most aesthetically and long lasting way possible. This includes criteria such as maximum preservation of sound tooth structure, avoidance of removable prosthesis, minimal surgical risk as well as cost effectiveness. (Öncü et al., 2016) (Dohan et al., 2006) (Mehta and Watson, 2008). Soft tissue augmentation is especially important in the aesthetic zone. The facial soft tissue parts will resorb quite quickly which should be prevented. The interdental papillae will disappear fast after extraction, and in addition, the enormous bone loss will influence the Gingiva. (Lacci and Dardik, 2010) The initial quality of the gingival tissue is important.
(Assoian et al., 1983) (Banks et al., 1998) (Gassling et al., 2010) (Streckbein et al., 2012) (Tolstunov, 2016) (FujiokaKobayashi et al., 2017) A thin biotype is less predictable then a thick biotype. The wound should be closed primarily without any tension. If the gingival tissue is weak or damaged, sloughing of the soft tissue is likely to occur and will lead to a compromised healing site due to contamination. Long-term clinical studies have shown that functional osseointegration is a predictable outcome. The dental implant therapy success depends not only on the osseointegration but also on aesthetic, function and harmony with the remaining dentition. (Kan, Rungcharassaeng and Lozada, 2005) (Schoenbaum, 2018) The most important factors that influence the esthetic outcome of the implant-supported restorations are as follows :Patient selection and smile line; Tooth position; Root position of the adjacent teeth; Biotype of the periodontium and tooth shape; The bony anatomy of the implant site; The position of the implant.

\section{CONCLUSION}

Satisfactory esthetic outcome is challenging in implantsupported restorations replacing missing anterior teeth. The maximization of the esthetic outcome depends mostly on the optimization of the algorithms specific to the pro-prosthetic, pro-implant and prosthetic stage. Hence gaining knowledge and aptitude towards connective tissue grafts in implant aesthetics will help in patient satisfaction as well as success of the implant.

\section{ACKNOWLEDGEMENTS}

The authors would like to acknowledge the Chancellor, Director of Academics, The Principal, Associate Dean of Research, The Vice Chancellor of Saveetha University. HOD and their Professors, Readers, Lecturers and their fellow Postgraduates, Department of Prosthodontics and Department of Pedodontic and Preventive Dentistry, Saveetha University, The support from their parents and from their family.

Conflict of Interest: The authors would like to declare that there is no conflict of interest among the authors.

\section{REFERENCES}

Anbu, R. T. et al. (2019) 'Comparison of the Efficacy of Three Different Bone Regeneration Materials: An Animal Study', European journal of dentistry, 13(1), pp. 22-28.

Ariga, P. et al. (2018) 'Determination of Correlation of Width of Maxillary Anterior Teeth using Extraoral and Intraoral Factors in Indian Population: A Systematic Review', World Journal of Dentistry, 9(1), pp. 68-75.

Ashok, V. and Ganapathy, D. (2019) 'A geometrical method to classify face forms', Journal of oral biology and craniofacial research, 9(3), pp. 232-235.

Assoian, R. K. et al. (1983) 'Transforming growth factorbeta in human platelets. Identification of a major storage site, purification, and characterization', The Journal of biological chemistry, 258(11), pp. 7155-7160. 
Banks, R. E. et al. (1998) 'Release of the angiogenic cytokine vascular endothelial growth factor (VEGF) from platelets: significance for VEGF measurements and cancer biology', British journal of cancer, 77(6), pp. 956-964.

Belser, U. C. et al. (1998) 'Aesthetic implant restorations in partially edentulous patients--a critical appraisal', Periodontology 2000. Wiley Online Library, 17(1), pp. 132-150.

Buser, D., Martin, W. and Belser, U. C. (2004) ‘Optimizing esthetics for implant restorations in the anterior maxilla: anatomic and surgical considerations', The International journal of oral \& maxillofacial implants, 19 Suppl, pp. 43-61.

Dohan, D. M. et al. (2006) 'Platelet-rich fibrin (PRF): a second-generation platelet concentrate. Part I: technological concepts and evolution', Oral surgery, oral medicine, oral pathology, oral radiology, and endodontics, 101(3), pp. e37-44.

Duraisamy, R. et al. (2019) 'Compatibility of Nonoriginal Abutments With Implants: Evaluation of Microgap at the Implant-Abutment Interface, With Original and Nonoriginal Abutments', Implant dentistry, 28(3), pp. 289-295.

Ehrenfest, D. M. D. et al. (2010) 'Three-Dimensional Architecture and Cell Composition of a Choukroun's Platelet-Rich Fibrin Clot and Membrane', Journal of Periodontology, pp. 546-555. doi: 10.1902/ jop.2009.090531.

Evaluation of Corrosive Behavior of Four Nickelchromium Alloys in Artificial Saliva by Cyclic Polarization Test:An in vitro Study' (2017) World Journal of Dentistry, 8(6), pp. 477-482.

Forna, N. and Agop-Forna, D. (2019) 'Esthetic aspects in implant-prosthetic rehabilitation', Medicine and pharmacy reports, 92(Suppl3), pp. S6-S13.

Fujioka-Kobayashi, M. et al. (2017) 'Optimized PlateletRich Fibrin With the Low-Speed Concept: Growth Factor Release, Biocompatibility, and Cellular Response', Journal of periodontology, 88(1), pp. 112-121.

Ganapathy, D. M., Kannan, A. and Venugopalan, S. (2017) 'Effect of Coated Surfaces influencing Screw Loosening in Implants: A Systematic Review and Meta-analysis', World Journal of Dentistry, 8(6), pp. 496-502.

Gassling, V. et al. (2010) 'Platelet-rich fibrin membranes as scaffolds for periosteal tissue engineering', Clinical oral implants research. Wiley Online Library, 21(5), pp. 543-549.

Gupta, P., Ariga, P. and Deogade, S. C. (2018) 'Effect of Monopoly-coating Agent on the Surface Roughness of a Tissue Conditioner Subjected to Cleansing and Disinfection: A Contact Profilometric Study', Contemporary clinical dentistry, 9(Suppl 1), pp. S122S126.

Jain, A. R. (2017a) 'Clinical and Functional Outcomes of Implant Prostheses in Fibula Free Flaps', World Journal of Dentistry, 8(3), pp. 171-176.
Jain, A. R. (2017b) 'Prevalence of Partial Edentulousness and Treatment needs in Rural Population of South India', World Journal of Dentistry, 8(3), pp. 213-217.

Kan, J. Y. K., Rungcharassaeng, K. and Lozada, J. L. (2005) 'Bilaminar subepithelial connective tissue grafts for immediate implant placement and provisionalization in the esthetic zone', Journal - California Dental Association, 33(11), pp. 865-871.

Kassab, M. M. (2010) 'Soft tissue grafting to improve implant esthetics', Clinical, cosmetic and investigational dentistry, 2, pp. 101-107.

Kloukos, D. et al. (2014) 'Indication and timing of soft tissue augmentation at maxillary and mandibular incisors in orthodontic patients. A systematic review', The European Journal of Orthodontics, pp. 442-449. doi: 10.1093/ejo/cjt073.

Lacci, K. M. and Dardik, A. (2010) 'Platelet-rich plasma: support for its use in wound healing', The Yale journal of biology and medicine, 83(1), pp. 1-9.

McAllister, B. S. and Haghighat, K. (2011) 'Clinical applications of a stem cell-based therapy for oral bone reconstruction', Stem Cell and Tissue Engineering. World Scientific Singapore, pp. 277-296.

Mehta, S. and Watson, J. T. (2008) 'Platelet rich concentrate: basic science and current clinical applications', Journal of orthopaedic trauma, 22(6), pp. 432-438.

Öncü, E. et al. (2016) 'Positive effect of platelet rich fibrin on osseointegration', Medicina oral, patologia oral y cirugia bucal, 21(5), pp. e601-7.

Prasad, D. K., Shetty, M. and Mehra, D. R. (2013) 'Anatomical considerations in implant selection and positioning,, The International journal of oral implantology: implantologist, 4(1), pp. 24-29.

Ranganathan, H., Ganapathy, D. M. and Jain, A. R. (2017) 'Cervical and Incisal Marginal Discrepancy in Ceramic Laminate Veneering Materials: A SEM Analysis', Contemporary clinical dentistry, 8(2), pp. 272-278.

Schoenbaum, T. R. (2018) Implants in the Aesthetic Zone: A Guide for Treatment of the Partially Edentulous Patient. Springer.

Streckbein, P. et al. (2012) 'Non-linear 3D evaluation of different oral implant-abutment connections', Journal of dental research, 91(12), pp. 1184-1189.

Tolstunov, L. (2016) Horizontal Alveolar Ridge Augmentation in Implant Dentistry: A Surgical Manual. John Wiley \&t Sons.

Varghese, S. S., Ramesh, A. and Veeraiyan, D. N. (2019) 'Blended Module-Based Teaching in Biostatistics and Research Methodology: A Retrospective Study with Postgraduate Dental Students', Journal of dental education, 83(4), pp. 445-450.

Zhang, W., Skrypczak, A. and Weltman, R. (2015) 'Anterior maxilla alveolar ridge dimension and morphology measurement by cone beam computerized tomography (CBCT) for immediate implant treatment planning', BMC oral health, 15, p. 65. 